\title{
Erratum to: Characterizing interwell connectivity in waterflooded reservoirs using data-driven and reduced-physics models: a comparative study
}

\author{
Emre Artun 1
}

Published online: 24 August 2016

(c) The Natural Computing Applications Forum 2016

\section{Erratum to: Neural Comput \& Applic DOI 10.1007/s00521-015-2152-0}

Unfortunately, in the original published article, Accuracy subsection of Section 3.2, Table 4 and Table 5 were not correct. The correct text for the Accuracy subsection and Tables 4 and 5 are given below.

Accuracy Prediction capabilities of each method can be analyzed by comparing each method's ability to indentify high-connectivity zones in the reservoir. As a qualitative comparison methodology, after ranking all of the 20 interwell connectivities between each of the five injectors and four producers, upper 10 values can be classified in the high-connectivity category and lower 10 values can be classified in the low-connectivity category. One can approximate the connectivity values for the numerical simulation model, by utilizing the average permeability between two wells and the distance between two wells (if two wells are close to each other and have a high-permeability streak between them, their connectivity would be the highest). The calculation is carried out using the following procedure: The logarithm of permeability between two wells is multiplied with the initial fractional-flow parameter which was calculated using the inverse-distance method (Eq. 9), and all connectivity values are normalized between 0 and 1 ( 1 represents the highest connectivity pair

The online version of the original article can be found under doi:10.1007/s00521-015-2152-0.

\section{Emre Artun}

artun@metu.edu

1 Petroleum and Natural Gas Engineering Program, Middle East Technical University, Northern Cyprus Campus, Mersin 10, Kalkanlı, 99738 Güzelyurt, Turkey in the field, and 0 represents the lowest connectivity pair in the field). These values are given in Table 5. After sorting the connectivity values obtained from the aforementioned procedure, as well as the predictions of data-driven and the reduced-physics models; it is seen that the data-driven and the reduced-physics models were able to correctly estimate 80 and $70 \%$ of each connectivity category, respectively:

- Data-driven model was able to predict the following high-connectivity pairs that match with the numerical model-based connectivities: 1, 6, 9, 12, 15, 18, 19, 20

- Reduced-physics model was able to predict the following high-connectivity pairs that match with the numerical model-based connectivities: 1, 2, 9, 12, 18, 19, 20

The purpose of this approach was to perform a fieldwide analysis that includes all injector-producer pairs and to distinguish higher-connectivity pairs from lower-connectivity pairs in the whole field. This process would help to understand which pairs would have greater impact on the field-wide production. An additional comparison methodology was to normalize the connectivity values for each injector such that the summation of connectivity values for a given injector adds up to 1 . This is a natural consequence of the formulation of the capacitance-resistance model, but has to be manually defined as an additional constraint for the artificial neural network and numerical model-based connectivities. The connectivity values obtained after applying this constraint to all approaches are also shown in Table 5. When the quantities of connectivities are compared with the numerical model, both approaches are comparable with correlation coefficient values of 0.86 for the reduced-physics modeling approach and 0.84 for the data-driven modeling approach. These acceptable accuracy levels indicate that both methods have similar prediction capabilities. It should be noted that this comparison should 
Table 4 Characteristics of data-driven and reduced-physics modeling approaches in various aspects

\begin{tabular}{|c|c|c|}
\hline & $\begin{array}{l}\text { Data-driven modeling } \\
\text { (ANN) }\end{array}$ & $\begin{array}{l}\text { Reduced-physics modeling } \\
\text { (CRM) }\end{array}$ \\
\hline $\begin{array}{l}\text { Accuracy (based on the specific example presented in this study and a qualitative } \\
\text { field-wide comparison) }\end{array}$ & $80 \%$ & $70 \%$ \\
\hline $\begin{array}{l}\text { Accuracy (based on the specific example presented in this study and a quantitative } \\
\text { injector-based comparison) }\end{array}$ & $\begin{array}{l}\text { Correlation } \\
\text { coefficient }=0.84\end{array}$ & Correlation coefficient $=0.86$ \\
\hline Data requirements & Flexible & Fixed \\
\hline Modeling approach & $\begin{array}{l}\text { Flexible data-driven } \\
\text { model }\end{array}$ & $\begin{array}{l}\text { Physics-based, include } \\
\text { assumptions }\end{array}$ \\
\hline Training algorithm & Flexible & Flexible \\
\hline Training speed & Fast & Fast \\
\hline Expertise requirements & Moderate & Moderate \\
\hline To develop the tool & $\begin{array}{l}\text { ANN background } \\
\text { needed }\end{array}$ & $\begin{array}{l}\text { Reservoir eng. background } \\
\text { needed }\end{array}$ \\
\hline To train & $\begin{array}{l}\text { ANN background } \\
\text { needed }\end{array}$ & $\begin{array}{l}\text { Optimization knowledge (for } \\
\text { fine-tuning) }\end{array}$ \\
\hline
\end{tabular}

Table 5 List of connectivity values from the numerical, data-driven and reduced-physics models

\begin{tabular}{|c|c|c|c|c|c|c|c|c|}
\hline \multicolumn{3}{|c|}{ Well pair } & \multicolumn{3}{|c|}{$\begin{array}{l}\text { Connectivity (based on qualitative, } \\
\text { field-wide comparison) }\end{array}$} & \multicolumn{3}{|c|}{$\begin{array}{l}\text { Connectivity (based on quantitative, } \\
\text { injector-based comparison) }\end{array}$} \\
\hline No. & Injector & Producer & Numerical & Data-driven & Reduced-physics & Numerical & Data-driven & Reduced-physics \\
\hline 1 & I1 & P1 & 1.000 & 1.000 & 1.000 & 0.694 & 0.572 & 0.990 \\
\hline 2 & $\mathrm{I} 2$ & $\mathrm{P} 1$ & 0.233 & 0.117 & 0.548 & 0.345 & 0.119 & 0.553 \\
\hline 3 & I3 & P1 & 0.169 & 0.206 & 0.057 & 0.146 & 0.178 & 0.053 \\
\hline 4 & I4 & P1 & 0.104 & 0.239 & 0.117 & 0.155 & 0.122 & 0.122 \\
\hline 5 & I5 & P1 & 0.104 & 0.213 & 0.126 & 0.155 & 0.169 & 0.126 \\
\hline 6 & I1 & P2 & 0.233 & 0.250 & 0.002 & 0.162 & 0.143 & 0.002 \\
\hline 7 & I2 & P2 & 0.104 & 0.177 & 0.003 & 0.155 & 0.181 & 0.003 \\
\hline 8 & I3 & P2 & 0.169 & 0.205 & 0.010 & 0.146 & 0.177 & 0.009 \\
\hline 9 & I4 & P2 & 0.233 & 0.903 & 0.178 & 0.345 & 0.462 & 0.186 \\
\hline 10 & I5 & $\mathrm{P} 2$ & 0.104 & 0.239 & 0.001 & 0.155 & 0.190 & 0.001 \\
\hline 11 & I1 & P3 & 0.104 & 0.293 & 0.003 & 0.072 & 0.168 & 0.003 \\
\hline 12 & $\mathrm{I} 2$ & $\mathrm{P} 3$ & 0.233 & 0.521 & 0.137 & 0.345 & 0.532 & 0.138 \\
\hline 13 & I3 & $\mathrm{P} 3$ & 0.169 & 0.184 & 0.033 & 0.146 & 0.159 & 0.031 \\
\hline 14 & I4 & P3 & 0.104 & 0.373 & 0.001 & 0.155 & 0.191 & 0.001 \\
\hline 15 & I5 & $\mathrm{P} 3$ & 0.233 & 0.402 & 0.106 & 0.345 & 0.319 & 0.106 \\
\hline 16 & I1 & $\mathrm{P} 4$ & 0.104 & 0.204 & 0.005 & 0.072 & 0.117 & 0.005 \\
\hline 17 & $\mathrm{I} 2$ & $\mathrm{P} 4$ & 0.104 & 0.165 & 0.303 & 0.155 & 0.168 & 0.306 \\
\hline 18 & I3 & $\mathrm{P} 4$ & 0.651 & 0.561 & 0.974 & 0.563 & 0.485 & 0.907 \\
\hline 19 & I4 & P4 & 0.233 & 0.438 & 0.662 & 0.345 & 0.224 & 0.691 \\
\hline 20 & I5 & P4 & 0.233 & 0.405 & 0.766 & 0.345 & 0.322 & 0.767 \\
\hline
\end{tabular}

not be generalized since it is only performed using the results from the synthetic case presented. For a fair comparison of accuracy and prediction abilities, different cases (especially real cases in more complex reservoirs and operational changes) should be considered as well. 